\title{
Hubungan Intensitas Penggunaan Media Sosial Dengan Kesehatan Mental Mahasiswa Pada Masa Pandemi Covid-19
}

\author{
Heri Gunawan* ${ }^{1}$, Ike Anggraeni ${ }^{1}$, Annisa Nurrachmawati ${ }^{2}$ \\ ${ }^{1}$ Departemen Biostatistika dan Kependudukan, Fakultas Kesehatan Masyarakat, Universitas \\ Mulawarman \\ ${ }^{2}$ Departemen Promosi Kesehatan, Fakultas Kesehatan Masyarakat, Universitas Mulawarman
}

Author's Email Correspondence (*): herigunawan1299@gmail.com

$(+628578889049)$

\begin{abstract}
ABSTRAK
Tingginya angka kasus positif COVID-19 menyebabkan masyarakat untuk mengubah kebiasaan dan cara berkomunikasi luring menjadi daring. Hal ini berdampak tingginya penggunaan media sosial pada remaja yang dapat berpengaruh terhadap perilaku remaja. Pengaruh dari penggunaan sosial media secara berlebihan dapat menyebabkan seseorang mengalami gangguan mental seperti stres, kecemasan, depresi, rendahnya self esteem, gangguan tidur, dan body image. Penelitian ini bertujuan untuk mengetahui hubungan dari intensitas penggunaan media sosial terhadap kesehatan mental pada mahasiswa Fakultas Kesehatan Masyarakat Universitas Mulawarman di masa pandemi COVID-19. Penelitian ini adalah penelitian analitik dengan desain cross sectional yang dilakukan pada 200 mahasiswa dengan teknik pengambilan sampel menggunakan simple random sampling. Instrumen yang digunakan yakni kuesioner Social Networking Time Use Scale (SONTUS) dan Depression Anxiety Stress Scale (DASS). Data dikumpulkan secara online menggunakan google form dan data dianalisis dengan uji korelasi pearson product moment. Hasil studi menunjukkan terdapat $24.5 \%$ mahasiswa mengalami stress sedang, $10.5 \%$ lainnya mengalami stress parah dan $6 \%$ mengalami stress sangat parah.. Korelasi positif ditemukan antara intensitas penggunaan media sosial dengan tingkat stres ( $\mathrm{p}$-value $=0,001, \mathrm{r}=0,270$ ). Kesimpulan bahwa semakin tinggi intensitas penggunaan media sosial maka semakin parah tingkat stres yang dialami. Temuan ini menunjukkan perlunya memberikan informasi kepada remaja mengenai bagaimana penggunaan media sosial yang tepat dan sehat untuk meminimalisir dampak negatif terutama kesehatan mental remaja.
\end{abstract}

Kata Kunci : Intensintas Media Sosial, Stres, Pandemi COVID-19

Published by:

Tadulako University

Address:

Jl.Soekarno Hatta KM 9. Kota Palu, Sulawesi Tengah,

Indonesia.

Phone: +628114120202

Email: Preventif.fkmuntad@gmail.com
Article history :

Received : 18062021

Received in revised form : 22062021

Accepted : 08072020

Available online 31122021

licensed by Creative Commons Attribution-ShareAlike 4.0 International License. 


\begin{abstract}
The pandemic of coronavirus disease (COVID-19) has been forced people changing their habits and ways of communication from offline to online. This situation also impact on the high usage of social media in adolescents which can affect behavior. The effect of excessive social media use lead to experience of mental disorders such as stress, anxiety, depression, low self-esteem, sleep disorders, and body image. This study aimed to examine the correlation between the intensity of social media use on mental health among students of Public Health Faculty Mulawarman University during the COVID-19 pandemic. This was a cross sectional study with 200 college students as sample which taken by simple random sampling. The study apply Social Networking Time Use Scale (SONTUS) and Depression Anxiety Stress Scale (DASS) instruments. Data were online collected and analyzed using pearson product moment test. The results showed there are $24.5 \%$ of students experiencing moderate stress, another $10.5 \%$ experiencing severe stress and 6\% experiencing very severe stress. The statistical analysis showed a weak positive correlation between the intensity of social media use and the level of stress ( $p$-value $=0.001, r=0.270)$. It can be concluded that the higher the intensity of social media use, the more severe the stress level is experienced. These findings indicate, its need to provide adolescent with information about how to make a healthy and appropriate relationship with social media to minimize the negative impact especially on their mental health.
\end{abstract}

Keywords : Intensity Social Media, Pandemic COVID-19, Stress

\title{
PENDAHULUAN
}

Pertumbuhan kasus COVID-19 saat ini telah menyebar di berbagai negara. Dengan tingginya angka kasus positif COVID-19 menyebabkan aktivitas masyarakat di berbagai negara jadi terganggu sehingga membuat masyarakat di dunia harus tetap diam dirumah untuk memutus mata rantai penyebaran COVID-19 (1). Hal ini menyebabkan masyarakat mengubah kebiasaan dan cara berkomunikasi luring menjadi daring. Kegiatan daring telah dilakukan di berbagai negara di belahan dunia dengan menggunakan teknologi data dan informasi yang saat ini tumbuh pesat. Di negara maju seperti Inggris, jumlah pengguna internet meningkat lebih dari dua kali lipat pada tahun 2020 (2). Peran internet terus menjadi berarti dalam kehidupan sosial, ekonomi serta politik di dunia global. Media sosial jadi layanan yang sangat kerap diakses oleh semua golongan masyarakat, terutama anak-anak atau remaja.

Media sosial menjadi salah satu perangkat yang banyak dicoba oleh para remaja untuk memenuhi kebutuhan interaksi sosialnya. Media sosial merupakan sebutan yang kerap digunakan untuk merujuk pada wujud media baru yang mengaitkan interaktif partisipasi. Konten media sosial yang kerap diakses antara lain Facebook, Instagram, Youtube, Google, Twitter serta Tiktok. Situs-situs tersebut terus tumbuh serta berperan selaku portal yang mudah untuk interaksi serta hiburan.

Berdasarkan data Worldwide Digital Population (2021) jumlah pengguna internet di dunia pada Januari 2021 sebanyak 4.66 miliar jiwa dan 4.2 miliar diantaranya pengguna aktif media 
sosial. Data statistik APJII (2020) menunjukkan bahwa pengguna internet di Indonesia sebanyak 196,71 juta jiwa serta pengguna media sosial sebesar 90,4 \% menjadi layanan peringkat teratas yang diakses dalam pemanfaatan internet oleh masyarakat Indonesia (3). Remaja merupakan salah satu pengguna aktif terbesar yang memakai sosial media sebagai sarana komunikasi yang utama dan mayoritas berusia 18-25 tahun mempunyai jumlah terbanyak dibanding dengan kelompok usia yang lain (4).

Tingginya penggunaan media sosial pada remaja dapat berpengaruh terhadap perilaku remaja tersebut (5). Media sosial merupakan elemen penting dalam melindungi kesehatan mental. Remaja dengan intensitas penggunaan media sosial yang tinggi menyebabkan interaksi sosialnya dapat bersifat tak langsung yaitu sosiabilitasnya dan kepekaan sosialnya cenderung rendah. Hal ini dapat berakibat kurang baik bagi kesehatan mental secara tidak langsung seperti timbulnya sikap anti sosial ataupun biasa disebut dengan sikap apatis (6). Berdasarkan beberapa studi lain yang telah dilakukan, diketahui penggunaan sosial media dapat menyebabkan seseorang mengalami gangguan mental seperti kecemasan, depresi, rendahnya self-esteem, gangguan tidur, dan body image (7).

Hasil studi di Jerman menunjukkan bahwa perubahan yang terjadi di masa pandemi COVID-19 anak-anak dan remaja memiliki dampak negatif bagi kesehatan mental hingga menyebabkan penurunan kualitas hidup (8). Hal ini menunjukkan bahwa kesehatan mental tidak lagi dipandang sebagai masalah sekunder, akan tetapi dapat dianggap sama pentingnya dengan kesehatan fisik (7).

Dalam studi penelitian yang dilakukan menyatakan terdapat dampak negatif ketergantungan media sosial terhadap kehidupan sosial individu tersebut dalam hal interpersonalnya dan penelitian lain juga menyebutkan kecemasan sosial, depresi dan rasa kesepian secara signifikan berpengaruh terhadap timbulnya ketergantungan pada media sosial. Ketergantungan akan media sosial ini tidak hanya terjadi pada kalangan anak SMP dan SMA, akan tetapi dapat juga terjadi pada mahasiswa di perguruan tinggi.

Dalam hal ini peneliti tertarik untuk meneliti mengenai penggunaan media sosial terhadap kesehatan mental pada mahasiswa, khususnya mahasiswa Fakultas Kesehatan Masyarakat Universitas Mulawarman. Keberhasilan upaya promotif maupun preventif kesehatan mental remaja akan lebih baik jika diketahui sebagai bentuk langkah awal dalam upaya meningkatkan perilaku kehidupan yang sehat dan kesejahteraan di semua usia. 
Berdasarkan uraian diatas dapat disimpulkan bahwa permasalahan penggunaan media sosial terhadap kesehatan mental pada remaja merupakan perihal yang penting untuk diketahui baik besaran pengaruh maupun faktor yang berhubungan dengan hal tersebut. Penelitian ini bertujuan untuk mengetahui permasalahan kesehatan mental pada mahasiswa serta mengetahui hubungan intensitas penggunaan media sosial terhadap kesehatan mental pada mahasiswa Fakultas Kesehatan Masyarakat Universitas Mulawarman di masa pandemi COVID-19.

\section{METODE}

Jenis penelitian ini adalah penelitian kuantitatif non ekperimental dengan rancangan cross sectional. Penelitian dilaksanakan di lingkungan kampus Fakultas Kesehatan Masyarakat Universitas Mulawarman, Samarinda. Waktu penelitian dimulai sejak bulan Maret hingga Mei 2021. Populasi pada penelitian ini sebanyak 383 mahasiswa aktif dari Angkatan 2017 - 2020 Fakultas Kesehatan Masyarakat Universitas Mulawarman dan sampel pada penelitian ini dipilih menggunakan teknik simple random sampling sehingga didapatkan jumlah sampel 192 orang.

Penelitian ini mengumpulkan data secara langsung dimana responden diminta mengisi kuesioner Social Networking Time Use Scale (SONTUS) untuk mengukur intensitas penggunaan media sosial dan kuesioner Depression Anxiety Stress Scale - 42 (DASS 42) untuk mengukur tingkat stres. Data kuesioner yang telah diisi kemudian akan dikumpulkan dan diperiksa oleh peneliti.

Variabel bebas pada penelitian ini adalah intensitas penggunaan media sosial dengan menggunakan lima indikator yakni penggunaan media sosial saat relaksasi dan waktu luang, keperluan akademik, saat merasa stres, ketika berada di tempat umum dan motif lainnya, kemudian hasil pengukuran dalam skala ordinal dengan empat tingkatan yakni rendah (skor 5 9), normal (skor 10 - 14), tinggi (skor 15 - 19) dan sangat tinggi (skor > 19), sedangkan variabel terikat penelitian ini adalah kesehatan mental pada tingkat stress yang dialami oleh mahasiswa kesehatan masyarakat selama masa pandemi COVID-19 dengan hasil pengukuran dalam skala ordinal dengan lima tingkatan yakni normal (skor 0 - 14), ringan (skor 15 - 18), sedang (skor 19 -25), parah (skor 26 -33) dan sangat parah (skor > 34). 
Selanjutnya dilakukan uji pearson product moment dengan tingkat kemaknaan $\alpha=0,05$ untuk menguji korelasi dan mengetahui arah hubungan antara intensitas penggunaan media sosial dan kesehatan mental pada tingkat stres.

\section{HASIL}

Dari penelitian yang telah dilakukan di Fakultas Kesehatan Masyarakat Universitas Mulawarman diperoleh hasil responden sebanyak 200 mahasiswa sebagai berikut :

Tabel 1

Distribusi karakteristik dan penggunaan media sosial pada responden

\begin{tabular}{|c|c|c|c|}
\hline No. & Variabel & $\begin{array}{r}\text { Frekuensi } \\
(\mathrm{n}=200)\end{array}$ & $\begin{array}{c}\text { Persentase } \\
(\%)\end{array}$ \\
\hline$(1)$ & $(2)$ & $(3)$ & $(4)$ \\
\hline 1. & Usia (mean,SD) & $19.42 \pm 1.157$ & \\
\hline \multirow[t]{3}{*}{2.} & Jenis Kelamin & & \\
\hline & Laki-laki & 28 & 14 \\
\hline & Perempuan & 172 & 86 \\
\hline \multirow[t]{5}{*}{3.} & Angkatan & & \\
\hline & 2017 & 76 & 38 \\
\hline & 2018 & 40 & 20 \\
\hline & 2019 & 22 & 11 \\
\hline & 2020 & 62 & 31 \\
\hline \multirow[t]{7}{*}{4.} & Jenis Media Sosial & & \\
\hline & Instagram & 181 & 28.8 \\
\hline & WhatsApp & 196 & 31.2 \\
\hline & Facebook & 42 & 6.7 \\
\hline & Twitter & 68 & 10.8 \\
\hline & Tik-Tok & 95 & 15.1 \\
\hline & Lainnya & 47 & 7.5 \\
\hline \multirow[t]{4}{*}{2.} & Lama penggunaan & & \\
\hline & $1-6$ bulan & 29 & 14.5 \\
\hline & $7-12$ bulan & 127 & 63.5 \\
\hline & $>12$ bulan & 44 & 22 \\
\hline \multirow[t]{5}{*}{3.} & Jenis fitur & & \\
\hline & Bersosialisasi & 136 & 25.7 \\
\hline & Mencari informasi & 190 & 35.9 \\
\hline & Pembaruan status & 102 & 19.3 \\
\hline & Posting foto atau video & 101 & 19.1 \\
\hline \multirow[t]{6}{*}{4.} & Jenis Informasi & & \\
\hline & Entertainment & 159 & 27.8 \\
\hline & Kesehatan & 171 & 29.9 \\
\hline & Politik & 54 & 9.5 \\
\hline & Teknologi & 90 & 15.8 \\
\hline & Lainnya & 97 & 17 \\
\hline
\end{tabular}

Sumber : Data Primer, 2021

Tabel 1 menunjukkan rata-rata umur responden adalah 19.42 dengan standar deviasi 1.157. Umur yang paling muda adalah 18 tahun dan umur paling tua 24 tahun. Mayoritas 
responden $(86 \%)$ adalah perempuan dengan sebagian besar responden berasal dari angkatan 2017 (38\%) dan angkatan 2020 (31\%). Media sosial yang paling banyak digunakan adalah WhatsApp (31.2\%) dan Instagram (28.8\%) dalam jangka waktu 7 - 12 bulan (63.5\%). Fitur yang sering digunakan oleh responden yaitu mencari informasi (35.9\%) dan bersosialisasi (25.7\%) jenis informasi kesehatan (29.9\%) dan entertainment $(27.8 \%)$ yang paling banyak dicari selama masa pandemi COVID-19.

Tabel 2

Jenis dan sumber informasi penyebab stres

\begin{tabular}{clcc}
\hline No. & \multicolumn{1}{c}{ Variabel } & $\begin{array}{c}\text { Frekuensi } \\
(\mathrm{n}=200)\end{array}$ & $\begin{array}{c}\text { Persentase } \\
(\%)\end{array}$ \\
\hline$(1)$ & \multicolumn{1}{c}{$(2)$} & $(3)$ & $(4)$ \\
\hline $1 . \quad$ Jenis Informasi & 13 & \\
& Entertainment & 25 & 6.5 \\
& Kesehatan & 124 & 12.5 \\
& Politik & 8 & 62 \\
& Teknologi & 30 & 4 \\
& Lainnya & & 15 \\
2. $\quad$ Sumber Informasi & 27 & 13.5 \\
& Teman sebaya & 25 & 12.5 \\
& Keluarga & 79 & 39.5 \\
& Figur publik & 37 & 18.5 \\
& Orang tak dikenal & 32 & 16 \\
\hline
\end{tabular}

Sumber : Data Primer, 2021

Tabel 2 menunjukkan bahwa jenis informasi dan sumber informasi yang menyebabkan stres mayoritas berasal dari informasi politik (62\%), kesehatan (12.5\%). Selanjutnya sumber informasi penyebab stres tertinggi berasal dari figur publik (39.5\%) serta orang tak dikenal $(18,5 \%)$.

Berikut merupakan uraian dari berbagai bentuk gejala stress yang dialami mahasiswa : 
Tabel 3

Gejala stres yang dialami mahasiswa

\begin{tabular}{|c|c|c|c|c|c|c|}
\hline No. & Bentuk Gejala & $\begin{array}{l}\text { Tidak } \\
\text { Pernah }\end{array}$ & $\begin{array}{l}\text { Kadang - } \\
\text { kadang }\end{array}$ & Sering & $\begin{array}{l}\text { Sangat } \\
\text { Sering }\end{array}$ & Total \\
\hline$(1)$ & $(2)$ & $(3)$ & $(4)$ & $(5)$ & $(6)$ & $(7)$ \\
\hline 1. & $\begin{array}{l}\text { Menjadi marah karena hal-hal } \\
\text { kecil/sepele }\end{array}$ & 17 & 54 & 20 & 9 & 100 \\
\hline 2. & $\begin{array}{l}\text { Cenderung bereaksi berlebihan pada } \\
\text { situasi }\end{array}$ & 35 & 43,5 & 16,5 & 5 & 100 \\
\hline 3. & Kesulitan untuk relaksasi/bersantai & 21.5 & 45 & 22,5 & 11 & 100 \\
\hline 4. & Mudah merasa kesal & 18,5 & 39,5 & 27,5 & 14,5 & 100 \\
\hline 5. & $\begin{array}{l}\text { Merasa banyak menghabiskan energi } \\
\text { karena cemas }\end{array}$ & 23,5 & 38,5 & 22 & 16 & 100 \\
\hline 6. & Tidak sabaran & 21 & 38 & 27 & 13,5 & 100 \\
\hline 7. & Mudah tersinggung & 32,5 & 43 & 15 & 9,5 & 100 \\
\hline 8. & Sulit untuk beristirahat & 21 & 35,5 & 25 & 18,5 & 100 \\
\hline 9. & Mudah marah & 22,5 & 45,5 & 20,5 & 11,5 & 100 \\
\hline 10. & $\begin{array}{l}\text { Kesulitan untuk tenang setelah sesuatu } \\
\text { yang mengganggu }\end{array}$ & 17,5 & 33 & 27,5 & 22 & 100 \\
\hline 11. & $\begin{array}{l}\text { Sulit mentoleransi gangguan-gangguan } \\
\text { terhadap hal yang sedang dilakukan }\end{array}$ & 24,5 & 45,5 & 23,5 & 6,5 & 100 \\
\hline 12. & Berada pada keadaan tegang & 30,5 & 47,5 & 14,5 & 7,5 & 100 \\
\hline 13. & $\begin{array}{l}\text { Tidak dapat memaklumi hal apapun } \\
\text { yang menghalangi anda untuk } \\
\text { menyelesaikan hal yang sedang Anda } \\
\text { lakukan }\end{array}$ & 40 & 44,5 & 12,5 & 3 & 100 \\
\hline 14. & Mudah gelisah & 23 & 37,5 & 27,5 & 12 & 100 \\
\hline
\end{tabular}

Sumber : Data Primer, 2021

Merujuk pada tabel 3 menunjukkan bahwa terdapat lima gejala stres yang sering dialami oleh mahasiswa yakni mudah merasa kesal (27,5\%), tidak sabaran (25\%), sulit untuk beristirahat $(18,5 \%)$, kesulitan untuk tenang setelah sesuatu yang menganggu $(27,5 \%)$ dan mudah gelisah $(27,5 \%)$. 
Tabel 4

Intensitas media sosial dan tingkat stres

\begin{tabular}{llcc}
\hline No. & \multicolumn{1}{c}{ Variabel } & $\begin{array}{c}\text { Frekuensi } \\
(\mathrm{n}=200)\end{array}$ & $\begin{array}{c}\text { Persentase } \\
(\%)\end{array}$ \\
\hline$(1)$ & \multicolumn{1}{c}{$(2)$} & $(3)$ & $(4)$ \\
\hline $1 . \quad$ & Intensitas media sosial & & \\
& Rendah & 45 & 22.5 \\
& Normal & 89 & 44.5 \\
& Tinggi & 57 & 28.5 \\
& Sangat Tinggi & 9 & 4.5 \\
2. $\quad$ Tingkat stres & & \\
$\quad$ Normal & 88 & 44 \\
& Ringan & 30 & 15 \\
& Sedang & 49 & 24.5 \\
& Parah & 21 & 10.5 \\
& Sangat Parah & 12 & 6 \\
\hline
\end{tabular}

Sumber: Data Primer, 2021

Merujuk pada tabel 3 terlihat bahwa hampir sebagian responden menggunakan media sosial dengan intensitas normal (44,5\%) sedangkan lainnya menggunakan media sosial dengan intensitas tinggi $(28,5 \%)$ serta terdapat $24.5 \%$ responden mengalami stress sedang, $10.5 \%$ lainnya mengalami stress parah dan $6 \%$ mengalami stress sangat parah.

Tabel 4

Hasil Uji Korelasi Data Intensitas Penggunaan Media Sosial dan Tingkat Stres

\begin{tabular}{|c|c|c|c|c|c|c|c|c|c|c|c|c|}
\hline \multirow{3}{*}{ Tingkat Stres } & \multicolumn{8}{|c|}{ Intensitas Media Sosial } & \multirow{2}{*}{\multicolumn{2}{|c|}{ Total }} & \multirow{3}{*}{$p$ value } & \multirow{3}{*}{$\begin{array}{c}\text { Koefisien } \\
\text { Korelasi }\end{array}$} \\
\hline & \multicolumn{2}{|c|}{ Rendah } & \multicolumn{2}{|c|}{ Normal } & \multicolumn{2}{|c|}{ Tinggi } & \multicolumn{2}{|c|}{ Sangat Tinggi } & & & & \\
\hline & $\mathrm{n}$ & $\%$ & $\mathrm{n}$ & $\%$ & $\mathrm{n}$ & $\%$ & $\mathrm{n}$ & $\%$ & $\mathrm{n}$ & $\%$ & & \\
\hline Normal & 25 & 28.4 & 42 & 47.7 & 18 & 20.5 & 3 & 3.4 & 88 & 100 & & \\
\hline Ringan & 9 & 30 & 12 & 40 & 8 & 26.7 & 1 & 3.3 & 30 & 100 & & \\
\hline Sedang & 8 & 16.3 & 22 & 44.9 & 18 & 36.7 & 1 & 2 & 49 & 100 & 0000 & \\
\hline Parah & 2 & 9.5 & 10 & 47.6 & 9 & 42.9 & 0 & 0 & 21 & 100 & , & 0,210 \\
\hline Sangat Parah & 1 & 8.3 & 3 & 25 & 4 & 33.3 & 4 & 33.3 & 12 & 100 & & \\
\hline Total & 45 & 22.5 & 89 & 44.5 & 57 & 28.5 & 9 & 4.5 & 200 & 100 & & \\
\hline
\end{tabular}

Sumber : Data Primer, 2021

Tabel 4 menunjukkan hasil analisis statistik menggunakan uji pearson product moment dengan tingkat kemaknaan 0,05 didapatkan nilai $p$-value $=0,001$ yang artinya terdapat hubungan antara intensitas penggunaan media sosial dan kesehatan mental (tingkat stres). Nilai koefisien korelasi $(r)=0.270$ bermakna bahwa terdapat korelasi yang lemah dan arah korelasi positif memiliki makna bahwa semakin tinggi intensitas penggunaan media 
sosial tinggi maka semakin tinggi pula tingkat stres yang dialami.

\section{PEMBAHASAN}

\section{Tingkat Stres pada Mahasiswa}

Beberapa jenis masalah kesehatan mental yang paling umum terjadi pada masyarakat salah satunya adalah stres. Stres merupakan suatu kondisi pada individu yang tidak menyenangkan dimana dari hal tersebut dapat menyebakan terjadinya tekanan fisik maupun psikologis pada individu (9). Hasil penelitian mengindikasikan bahwa terdapat permasalahan kesehatan mental pada 4 dari 10 mahasiswa dengan prevalensi $24.5 \%$ mahasiswa mengalami stres sedang, 10.5\% lainnya mengalami stres parah bahkan ditemukan 6\% mengalami stres sangat parah. Temuan ini selaras dengan studi Liang (2020) yang mengindikasikan $40.4 \%$ mahasiswa mengalami permasalahan mental dan Ma et.al (2020) yang menemukan terdapat $45 \%$ mahasiswa mengalami stres $(10,11)$.

Gejala stres yang lebih dominan dialami oleh remaja yang mengalami stres dari aspek secara fisik yaitu merasa kondisi tubuh kadang-kadang tegang, cemas, kelelahan dan kurang istirahat (12). Hasil penelitian menunjukkan bahwa 18,5\% mahasiswa sering mengalami sulit untuk beristirahat. Lebih lanjut studi Ferrita (2010) memaparkan remaja yang mengalami stres menyebabkan penggunaan media sosial lebih tinggi untuk menghibur diri sehingga melewatkan waktu untuk tidur malam. Hal yang paling ekstrim mengenai gejala stres dari aspek secara psikologis misalnya rasa cemas yang berlebihan, merasa ketakutan, depresi dan munculnya gejala stres lainya (14).

Stres pada mahasiswa penting untuk dihindari dan dikelola karena menurut Bressert (2016) stres dapat berdampak terhadap empat aspek dari individu yaitu fisik, kognitif, emosi dan perilaku. Salah satunya dampak stres pada aspek emosi, diantaranya mudah sensitif dan mudah marah, frustasi dan merasa tidak berdaya serta dampak stres pada aspek kognitif ditandai dengan adanya kebingungan, sering lupa, kekhawatiran dan kepanikan. Hasil penelitian mengungkapkan bahwa hal yang sering dirasakan oleh mahasiswa adalah tidak sabaran, mudah merasa kesal, mudah gelisah dan kesulitan untuk tenang setelah terjadi sesuatu yang menganggu individu tersebut. Hal ini tentu saja dapat menyebabkan mahasiswa akan memiliki masalah dalam kehidupan sehari-hari, yang tidak hanya dapat merusak interaksi atau hubungan dengan orang lain, juga dapat menurunkan prestasi akademik dan kualitas hidup.

Dalam upaya mengelola situasi yang menekan, individu perlu melakukan perubahan kognitif maupun perilaku untuk memperolah rasa aman dalam pada diri sendiri atau disebut 
coping. Coping religius positif terbukti menghasilkan kesehatan mental yang lebih baik ketika berhadapan dengan peristiwa kehidupan yang penuh tekanan. Penghayatan individu

dari pengalaman religus akan berdampak pada kemampuan yang lebih baik dalam mengambil nilai- agama yang dianutnya dalam mengatasi ketegangan dalam menghadapi masalah serta memiliki ketenangan yang lebih baik (15).

\section{Hubungan Intensitas Penggunaan Media Sosial dan Tingkat Stres}

Analisis statistik menunjukkan bahwa terdapat hubungan yang bermakna antara intensitas penggunaan media sosial dengan kesehatan mental pada tingkat stres yang dialami oleh mahasiswa Fakultas Kesehatan Masyarakat Universitas Mulawarman dengan nilai korelasi yang bernilai positif, sehingga semakin tinggi intensitas dari penggunaan media sosial maka akan semakin parah tingkat stres. Hal ini terbukti dari beberapa responden pada penelitian dengan intensitas media sosial yang tinggi, memiliki tingkat stres dengan kondisi parah. Sebaliknya, mayoritas responden dengan intensitas penggunaan media sosial yang rendah atau normal, memiliki tingkat stres yang rendah atau normal. Hasil ini sejalan dengan penelitian Handikasari et al (2018) yang menyatakan bahwa terdapat hubungan yang bermakna antara intensitas penggunaan media sosial dengan gejala depresi dan penelitian Gao et al. (2020) menunjukkan terdapat prevalensi tinggi masalah kesehatan mental dengan seringnya paparan media sosial selama wabah COVID-19.

Dalam penelitian lain yang dilakukan di India menunjukkan bahwa $88 \%$ anak-anak yang tinggal pada perkotaan di India mengalami peningkatan secara signifikan terhadap paparan durasi layar smartphone. Hal ini disebabkan karena banyak anak-anak atau remaja beralih ke media sosial selama pandemi COVID-19, dengan kebiasaan menghabiskan banyak waktu di media sosial paling lama 3 - 4 jam (16). Serta kurangnya aktivitas fisik selama masa pandemi COVID-19 yang kemudian dihubungkan dengan peningkatan durasi penggunaan media sosial (17).

WhatsApp dan Instagram menjadi jenis media sosial yang paling sering digunakan pada kalangan mahasiswa/i di Fakultas Kesehatan Masyarakat seperti yang ditunjukkan dalam penelitian ini terdapat $31.2 \%$ pengguna instagram dan $28.8 \%$ pengguna whatsapp. Kemasifann instagram khususnya dikalangan mahasiswa menjadikan instagram sangat banyak penggunanya (18). Hal ini pun sejalan dengan penelitian sebelumnya yang dilakukan Padmonobo (2019) yang menunjukkan adanya korelasi positif antara stres akademik dengan perilaku penggunaan instagram. Instagram merupakan media sosial yang menggunakan foto 
atau video sebagai bentuk komunikasi. Interaksi di dalam instagram adalah dengan menjadi pengikut (followers) akun pengguna instagram lain. Komunikasi dalam instagram diwakilkan dengan memberi tanda suka (like) dan memberi komentar pada foto atau video yang telah diunggah pengguna lain (19). Namun, pada penelitian pada remaja perempuan menunjukkan bahwa likes dan jumlah followers dihubungkan dengan penghargaan orang lain terhadap tampilan fisik mereka dan dapat meningkatkan penghargaan (20). Hal ini dapat menyebabkan peningkatan suasana hati (mood) negatif dan menurunkan harga diri (selfesteem) sehingga dapat menjadi pemicu stressor bagi para pengguna instagram.

Pada penelitian Sampasa-Kanyinga \& Lewis (2015) mengungkapkan bahwa seseorang yang mengakses situs jejaring sosial lebih dari 2 jam setiap harinya akan lebih berisiko terhadap buruknya kesehatan mental. Hal ini juga diperkuat oleh penelitian yang dilakukan oleh Setyawan (2016), menunjukkan bahwa peningkatan durasi penggunaan media sosial memiliki hubungan dengan kestabilan emosi pada remaja. Media sosial yang berisi konten dimana berperan sebagai stimulus emosional didapatkan oleh individu dengan intensitas tinggi, maka terjadi perubahan suasana hati yang menyebabkan perubahan emosi individu atau dinamakan emosi yang tidak stabil (22). Selain itu, konten yang ditampilkan di media sosial akan semakin berpusat pada krisis kesehatan mental itu sendiri. Hal ini yang menimbulkan pertimbangan baru terhadap kesejahteraan emosional remaja (23). Hal ini juga telah disebutkan pada penelitian Odgers \& Jensen (2020) menyebutkan bahwa penggunaan media sosial sebelum masa pandemi COVID-19 sering menyebutkan potensi implikasi negatif bagi kesehatan mental remaja.

Banyak faktor yang dapat menyebabkan seorang individu mengalami stres. Soliha (2015) menuliskan terdapat beberapa faktor yang mempengaruhi tingkat stres, salah satunya lingkungan. Lingkungan dengan kebiasaan tidak dapat lepas dari smartphone khususnya media sosial dapat menyebabkan seseorang kurang berkomunikasi dengan orang di sekitarnya dan menghabiskan waktunya dengan media sosial. Akan tetapi, kondisi pandemi COVID - 19 menyebabkan adanya physical distancing sehingga para remaja terhubung dengan teman sebayanya melalui berbagai cara menggunakan media sosial selama pandemi COVID-19 (23). Pernyataan tersebut terbukti dengan kuesioner penggunaan media sosial mengenai alasan penggunaan media sosal yang sebagian besar responden memilih jawaban mencari informasi $(35,9 \%)$ dan bersosialisasi $(25,7 \%)$, dengan kata lain individu di lingkungan responden juga menggunakan media sosial untuk saling berkomunikasi. Selain itu, sesuai dengan hasil kuesioner menunjukkan mayoritas responden menggunakan media sosial 
sudah lebih dari 7 - 12 bulan (63,5\%). Waktu yang tidak sebentar artinya, sudah sangat lama remaja mengenal media sosial dan seolah-olah media sosial adalah kebutuhan primer.

Hasil penelitian ini menunjukkan perlu adanya kontrol diri dan pengawasan dari orang tua terhadap intensitas penggunaan media sosial sehingga dapat membantu remaja di kalangan mahasiswa untuk meminimalisir dan mencegah dampak dari tingginya intensitas penggunaan media sosial terhadap kesehatan mental.

Perilaku yang berhubungan dengan masalah kesehatan mental, pada umumnya terjadi pada indivdu yang memiliki kontrol diri yang rendah (26). Sehingga pada masa pandemi COVID-19 proses peningkatan kontrol diri menjadi sangat penting bagi seorang remaja karena penggunaan media sosial pada remaja di masa pandemi menjadi lebih tinggi dibandingkan dengan kehidupan sebelum pandemi, sehingga akan menjadikan remaja lebih beresiko terhadap dampak negatif yang dapat ditimbulkan (27). Hal ini sejalan dengan penelitian Nurhanifa et al. (2020) menyebutkan 66,8\% remaja di SMAN 10 Bandung memiliki kontrol diri yang sedang dalam penggunaan media sosial artinya remaja berada pada kemampuan yang cukup untuk mengendalikan kognitif, keputusan dan perilakunya dalam penggunaan media sosial.

Penggunaan media sosial dengan intensitas tinggi harus ditangani sebagai upaya untuk meminimalisir terjadinya dampak negatif yang dapat ditimbulkan pada remaja terutama pada kesehatan mental. Sehingga perlu dilakukan pencegahan agar remaja dapat mengurangi intensitas untuk terhubung dengan media sosial dan juga mencegah agar intensitas penggunaan media sosial tidak berlanjut menjadi semakin tinggi. Hal ini dikarenakan masa remaja menjadi tolak ukur menuju masa dewasa dalam tahap perkembangannya, sehingga jika sejak remaja penggunaan media sosial berlebih tanpa adaya upaya pencegahan maka memungkinkan intensitas penggunaan media sosial akan meningkat seiring bertambahnya usia dan tentu hal ini akan berdampak juga pada kesehatan mental pada remaja tersebut.

Pencegahan yang dapat dilakukan pada remaja pengguna media sosial dengan intensitas rendah hingga sangat tinggi yakni dengan memberikan edukasi atau pendidikan kesehatan terkait penggunaan media sosial yang sehat, tepat dan seperlunya saja, sehingga remaja tidak selalu memiliki keinginan untuk selalu terhubung dengan media sosial serta edukasi tentang dampak negatif atau bahaya dari penggunaan media sosial berlebihan. Hal ini bertujuan untuk membantu remaja dalam mengganti pola pikirannya menjadi lebih rasional 
dan dapat membuat remaja memiliki perilaku adaptif dalam menggunakan media sosial, seperti adanya perilaku mengontrol penggunaan media sosial (29).

\section{KESIMPULAN DAN SARAN}

Berdasarkan hasil penelitian ini, dapat disimpulkan bahwa terdapat masalah kesehatan mental pada $41 \%$ mahasiswa dan terdapat hubungan yang bermakna antara intensitas penggunaan media sosial dengan kesehatan mental dengan arah hubungan/korelasi positif dengan makna semakin tinggi intensitas penggunaan media sosial semakin tinggi keparahan tingkat stres yang dialami. Temuan ini menunjukkan perlunya memberikan informasi kepada remaja mengenai bagaimana penggunaan media sosial yang tepat dan sehat untuk meminimalisir dampak negatif terutama kesehatan mental remaja.

\section{DAFTAR PUSTAKA}

1. Siahaan M. Dampak Pandemi Covid-19 Terhadap Dunia Pendidikan. 2020;1(1):73-80.

2. News B. UK internet use doubles in 2020 due to pandemic. CoronaVirus Pandemic. 2020;1.

3. APJII. Laporan Survei Internet APJII 2019 - 2020. Asos Penyelenggara Jasa Internet Indones [Internet]. 2020;2020:1-146. Available from: https://apjii.or.id/survei

4. Handikasari RH, Jusup I, Johan A. Hubungan Intensitas Penggunaan Media Sosial dengan Gejala Depresi Mahasiswa Kedokteran. J Kedokt Diponegoro. 2018;7(2):919-34.

5. Pratama BA, Setiyaningsih R. Efek Penggunaan Jejaring Sosial terhadap Perilaku Seksual Pranikah pada Remaja di SMP Negeri 1 Sukoharjo. Indones J Med Sci. 2015;2(2):56-64.

6. Taqwa MI. Intensitas Penggunaan Media Sosial Instagram Stories dengan Kesehatan Mental. 2018;(April). Available from: papers2://publication/uuid/512EBCE8-D6354348-A67D-22DD52988F4C

7. Nadya R, M.B.P. RL, Saputra WT. Penggunaan Media Sosial Sehat Untuk Mencegah Gangguan Mental. Ikraith-Abdimas. 2020;3(3):189-97.

8. Ravens-Sieberer U, Kaman A, Erhart M, Devine J, Schlack R, Otto C. Impact of the COVID-19 pandemic on quality of life and mental health in children and adolescents in Germany. Eur Child Adolesc Psychiatry [Internet]. 2021; Available from: https://doi.org/10.1007/s00787-021-01726-5

9. Manurung. Terapi Reminiscence. Jakarta: CV. Trans Info Media; 2016.

10. Ma Z, Liu X. Mental health problems and correlates among 746217 college students during the coronavirus disease 2019 outbreak in China. 2021;1-10.

11. Liang L, Ren H, Cao R, Hu Y, Qin Z, Li C. The Effect of COVID-19 on Youth Mental Health. 2020;(1163).

12. Gao J, Zheng P, Jia Y, Chen H, Mao Y, Chen S, et al. Mental health problems and social media exposure during COVID-19 outbreak. PLoS One [Internet]. 2020;15(4):1-10. Available from: http://dx.doi.org/10.1371/journal.pone.0231924

13. Ferrita K. Hubungan Antara Derajat Insomnia dengan Beratnya Kebiasaan Merokok pada Mahasiswa Universitas Muhammadiyah Malang. Univ Muhammadiyah Malang. 2010 
14. Bandiyah. Lanjut Usia dan Keperawatan Gerontik. Yogyakarta: Nuha Medika; 2011.

15. Thomas J, Barbato M. Positive Religious Coping and Mental Health among.

16. 2020;(2012).

17. warnam S. Effect of Social Media Use on Adolescent Mental Health during Lockdown India. Deemed Univ. 2020;1-15.

18. Dieris-Hirche J, Bottel L, Bielefeld M, Steinbüchel T, Kehyayan A, Dieris B, et al. Media use and Internet addiction in adult depression: A case-control study. Comput Human Behav. 2017;68:96-103.

19. Padmonobo AJP. Perilaku Penggunaan Instagram ditinjau dari Stres Akademik pada Mahasiswa. Unika Soegijapranika Semarang. 2019;

20. Ridgway J, Clayton R. Instagram unfiltered: Exploring associations od body image satisfaction, Instagram \#selfie posting, and negative romantic relationship outcomes. Cyberpsychology, Behav Soc Netw. 2016;19(1):2-7.

21. Chua T., Chang L. Follow me and like my beautiful selfies: Singapore teenage girls' engagement in self-presentation and peer comparison on social media. Comput Human Behav. 2016;55:190-7.

22. Sampasa-Kanyinga H, Lewis RF. Frequent Use of Social Networking Sites is Associated with Poor Psychological Functioning among Children and Adolescents. Cyberpsychology, Behav Soc Netw. 2015;18(7):380-5.

23. Setyawan M. Hubungan antara durasi penggunaan media sosial dengan kestabilan emosi pada pengguna media sosial usia dewasa awal. Sanata Dharma Univ. 2016;

24. Hamilton JL, Nesi J, Choukas-bradley S. Teens and social media during the COVID-19 pandemic : Staying socially connected while physically distant. 2020;

25. Odgers C., Jensen M. Annual Research Review: Adolescent Mental Health in The Digital Age: Facts, Fears and Future Directions. J Child Adolesc Psychiatry. 2020;61:336-48.

26. Soliha SF. Tingkat Ketergantungan Pengguna Media Sosial dan Kecemasan Sosial. Interak J Ilmu Komun. 2015;4(1):1-10.

27. Dewall N. Self Control : Teaching Students About Their Greatest Inner Strength. Am Psychol Assoc. 2014;24(3).

28. Ni MY, Yang L, Leung CMC, N. L, Yao I. X, Wang Y, et al. Mental Health, Risk Factors, and Social Media Use During the COVID-19 Epidemic and Cordon anitaire Among the Community and Health Professionals in Wuhan, China: Cross-Sectional Survey. JMIR Ment Heal. 2020;7(5).

29. Nurhanifa A, Widianti E, Yamin A. Kontrol diri dalam penggunaan media sosial pada remaja. J Ilmu Keperawatan Jiwa [Internet]. 2020;3(4):527-40. Available from: https://journal.ppnijateng.org/index.php/jikj/article/download/727/374

30. Aprilia R, Sriati A, Hendrawati S. Tingkat Kecanduan Media Sosial pada Remaja. 2018;3(1):41-53. 